\title{
Enhancing health care services through close collaboration between medical and dental professionals
}

Edward CM Lo *, FCDSHK (Com Dent), FHKAM (Dental Surgery)

Faculty of Dentistry, The University of Hong Kong, Hong Kong

Hong Kong Med J 2014;20:92-3

*hrdplcm@hku.hk

DOI: $10.12809 / \mathrm{hkmj} 144249$

In a modern society like Hong Kong, the rapid expansion of medical knowledge and sophisticated technology has meant that health care services have become more and more specialised and many medical specialties have become established. Currently, there are 15 specialty Colleges in the Hong Kong Academy of Medicine (HKAM) and most of these also have their own subspecialties. On one hand, this type of highly specialised health care service can ensure that the medical practitioners are able to master advanced medical knowledge and technology in providing care for their patients. However, this system also risks providing fragmented care, such that doctors only provide treatments in the disciplines they are specialised in and ignore other health care needs.

The development of dentistry in Hong Kong follows the British model, in which a distinct dental profession was established and the scope of work by dentists was defined in law. ${ }^{1}$ A separate undergraduate curriculum was also established within the university for training dentists. It is expected that when people have problems with their teeth or other oral tissues, they visit a dentist to determine the problem and receive oral health care services accordingly. A key health message was that people should visit dentists regularly for check-ups and preventive care. ${ }^{2}$ Under this health care system, dentists focus on the diagnosis and treatment of oral diseases and tend to overlook their patient's other health problems, which are regarded the responsibility of medical practitioners. Likewise, doctors too tend not to deal with the oral health problems of their patients.

The above-mentioned health care development and arrangement sees oral health problems as being separate from general health and to be handled by dentists on their own. This is in sharp contradiction to human biology, which clearly shows that the mouth is part of the body and connected to other tissues and organs. Likewise, the health and diseases of the mouth and systemic health are closely related. For example, uncontrolled diabetes mellitus and impaired immunity are associated with more severe periodontal diseases, ${ }^{3,4}$ and gastroesophageal reflux disease can cause teeth erosion. ${ }^{5}$ These health problems can only be satisfactorily managed by treating both the oral disease/problem and the systemic disease at the same time through collaboration between dental and medical practitioners. Take tobacco use as another example. Smoking can cause many systemic diseases as well as aggravate periodontal diseases. To enhance the quality and effectiveness of dental care services, dentists should enquire into their patient's smoking habits, provide smoking cessation advice, and make referrals to other health care providers as necessary. However, a recent survey of Hong Kong dentists found that only half of them provided such advice routinely; the main reported barriers being lack of training, lack of confidence, and fear of damaging relationship with their patients. ${ }^{6}$ Furthermore, since many individuals visit dentists regularly for checkups, it makes good sense to use these opportunities to look out for the oral manifestations of systemic diseases in them, give appropriate health advice, and make referrals to doctors as necessary. ${ }^{7,8}$

The need for more collaboration between dental and medical professionals to provide better patient health care services is not one-sided. Doctors should also pay attention to the oral health condition of their patients and work closely with dentists as necessary, to ensure holistic health care. For example, dental caries (tooth decay) is one of the commonest diseases of Hong Kong preschool children, and affects more than half of them by the age of 5 years. ${ }^{9}$ Paediatricians and other doctors should have a good understanding of this important epidemic, give appropriate health advice, and make appropriate early referrals to dentists. ${ }^{10}$ The importance of maintaining good oral hygiene and oral health in the prevention of pneumonia among nursing home residents, ${ }^{11}$ as well as in the management of patients with diabetes, ${ }^{3}$ cardiovascular diseases, ${ }^{12}$ and chronic kidney disease ${ }^{13}$ have been amply reported. Patients with dental emergencies such as traumatic injury to teeth may turn up in a medical clinic, but some doctors may not be well-prepared to provide primary management of such a problem because of a lack of education in this field of practice. ${ }^{14} \mathrm{~A}$ recent government oral health survey in Hong Kong found that around $10 \%$ of the adults, who sought professional health care due to toothaches which 
disturbed sleep, visited a doctor instead of a dentist. ${ }^{9}$ Thus, there is a need for the medical practitioners in Hong Kong to have a good appreciation of the common oral diseases and provide the appropriate care, including making referrals.

Oral and systemic health are certainly related. In order to provide high-quality health service, an interdisciplinary and holistic approach should be adopted. ${ }^{14}$ To enhance the health care of Hong Kong inhabitants, there should be more collaboration between the medical and dental professionals. In fact, one of the objectives of the HKAM to improve the health care of Hong Kong citizens is to promote and foster a spirit of cooperation among medical professionals (dental practitioners being included by implication, as their college is one of 15 HKAM Colleges already referred to). As a possible action plan, the current medical and dental curricula could be enriched by adding more interdisciplinary education on the relationship between oral and systemic health and disease and the need for collaborative management of patients. This can be supplemented by organising more continuing medical education programmes involving the two professions. The development of a cohesive public health policy inclusive of oral health could also greatly benefit the health of Hong Kong residents.

\section{References}

1. Davies WI, Corbet EF, Chiu GK. Dentistry's development in Hong Kong. Int Dent J 1997;47:137-41.

2. Davies RM. The prevention of dental caries and periodontal disease from the cradle to the grave: what is the best available evidence? Dent Update 2003;30:170-
6,178-9.

3. Lalla E, Papapanou PN. Diabetes mellitus and periodontitis: a tale of two common interrelated diseases. Nat Rev Endocrinol 2011;7:738-48.

4. Mays JW, Sarmadi M, Moutsopoulos NM. Oral manifestations of systemic autoimmune and inflammatory diseases: diagnosis and clinical management. J Evid Based Dent Pract 2012;12(3 Suppl):265-82.

5. Ranjitkar S, Smales RJ, Kaidonis JA. Oral manifestations of gastroesophageal reflux disease. J Gastroenterol Hepatol 2012;27:21-7.

6. Li KW, Chao DV. Current practices, attitudes, and perceived barriers for treating smokers by Hong Kong dentists. Hong Kong Med J 2014;20:94-101.

7. Islam NM, Bhattacharyya I, Cohen DM. Common oral manifestations of systemic disease. Otolaryngol Clin North Am 2011;44:161-82.

8. Greenberg BL, Glick M. Assessing systemic disease risk in a dental setting: a public health perspective. Dent Clin North Am 2012;56:863-74.

9. Oral health survey 2011. Hong Kong: Department of Health; 2013.

10. Krol DM. Children's oral health and the role of the pediatrician. Curr Opin Pediatr 2010;22:804-8.

11. El-Solh AA. Association between pneumonia and oral care in nursing home residents. Lung 2011;189:173-80.

12. Lam OL, Zhang W, Samaranayake LP, Li LS, McGrath C. A systematic review of the effectiveness of oral health promotion activities among patients with cardiovascular disease. Int J Cardiol 2011;151:261-7.

13. Akar H, Akar GC, Carrero JJ, Stenvinkel P, Lindholm B. Systemic consequences of poor oral health in chronic kidney disease patients. Clin J Am Soc Nephrol 2011;6:21826.

14. Migliorati CA, Madrid C. The interface between oral and systemic health: the need for more collaboration. Clin Microbiol Infect 2007;13 Suppl 4:11-6. 